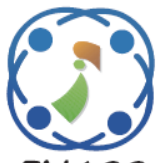

\title{
Optimal Allocation and Sizing of Multiple DG in Radial Distribution System Using Binary Particle Swarm Optimization
}

\author{
Banka Jyothsna Rani ${ }^{1 *} \quad$ Ankireddipalli Srinivasula Reddy ${ }^{2}$ \\ ${ }^{I}$ Government Model Residential Polytechnic, India \\ ${ }^{2}$ CMR Engineering College, India \\ * Corresponding author’s Email: jyothsna.jyothsna3@gmail.com
}

\begin{abstract}
In modern days, utility grids are facing major issues in the power system due to an uninterrupted load development and shortage of capital investment in transmission systems. Due to this, network is not capable to meet the estimated demand and transfer the produced power from the integrated power generation into the distribution network. This may generate high power losses in the distribution side that also disturbs the overall efficiency of the network. By employing an optimal placement of Distributed Generation (DG) in power systems is the only way to minimize this kind of problems in economical and practical way. DG has several benefits over centralized power generations that comprising system steadiness, improvement and dismissing transmission/distribution system bottleneck to meet the power demand. So in this paper, Binary Particle Swarm Optimization (BPSO) is used for optimal DG reconfiguration. BPSO iteratively moves the DG in each load bus of the test system that provides the smallest value of the objective function, which is considered as the finest candidate for DG connection. This method is simulated on IEEE 69-bus system that showed enhancement in voltage profile and decrease in power loss compared to other optimization methods.
\end{abstract}

Keywords: Binary particle swarm optimization (BPSO), Distributed generation (DG), Optimal placement, Power loss, Voltage profile.

\section{Introduction}

In recent years, there has been a developing concern in Renewable Energy Sources (RES) due to the growing demand of the electricity and substantial reduction of fossil fuel. For that reason, research on the incorporation of DG into the distribution system has turned out to be very popular. The incorporation of DG is anticipated to play an important part in the electric power system $[1,2]$. DG is one of the small-scale power generations that is frequently associated with distribution system. DG is playing a major role in minimizing the losses and enhancing voltage stability in power systems [3], [4]. Along with these assistances, use of DG components of the non-optimal location can lead to disadvantages. As a result, the choice of best placement for the connection and the desirable size of DG units in the distribution system is a complicated optimization issue [5]. Currently, several researchers improved the existing procedures by altering the development and hybridization of different algorithms [6]. Numerous methods used to recognize both fundamental and progressive methods to solve DG location and sizing problems [7].

The optimal location of DG is essential to attain the maximum profits with less investment. After deregulation of power system, non-utility corporations are investing in distribution network to meet the active power demand (MW) and get the maximum profit [8]. Growing machineries play an important role in the development of power generation; DGs could rapidly counter the demand variants to carry out the demand side management [9]. Therefore, it is extremely important to allocate each DG at the correct position to evade the poor performance of the electrical network [10,11]. More 
than a few sets of rules were used for DG employment like Artificial Bee Colony Algorithm (ABC), Particle Swarm Optimization (PSO), Modified Teaching-Learning Based Optimization (MTLBO), Genetic Algorithm (GA), and Harmony Search Algorithm (HSA) [12, 13]. The main disadvantages of all the above approaches are insufficient reactive power support in distributed network that leads to higher power losses, bus voltage reduction, low convergence speed and obtain nearby optimal solutions only. The DG units have the ability to supply the reactive power when connected to any of the bus in the network [14]. Additionally, the non-optimal location of DG can result in increase of the system losses that makes the voltage profile lower than the permissible range. Therefore, there are numerous problems concerning the incorporation of DGs with the existing power system [15]. From that, it is essential to establish a new procedure that can be robust, efficient, and comparatively more consistent with the other constraints [16]. Here, network reconfiguration based on Binary Particle Swarm Optimization (BPSO), which is recommended in this research work. The velocity update formulation of BPSO is same as PSO (Particle Swarm Optimization) algorithm, but the position update formula is different. During the initialization process of BPSO particle population, the result of the issues is transformed into binary code and particle's position vectors can take the value as 0 or 1 . Then these vectors drawn from the n-dimensional binary space (B) into the real numbers $(F)$ that means a particle's location must belong to $\mathrm{B}$ that is considered by $\mathrm{F}$ to discover the ideal distribution system structure for power loss minimization. The main objective of this paper is to minimize the power loss and improve the voltage profile in the system by employing DG. This algorithm is applied on IEEE 69-bus Radial Distribution Network (RDN), and then it has been verified by BPSO. This proposed work gives an efficient performance over the distributed system when compared with other traditional techniques.

The paper is organized as follows. Section 2 provides a brief description of the related works. Section 3 focuses on BPSO methodology. In section 4 , comparative study of the results and discussion of proposed and existing system is presented. Section 5 gives a summary of this paper.

\section{Literature review}

Several researchers recommended many techniques in the field of optimal allocation of DG. In this scenario, a brief evaluation of some important contributions to the existing literatures is represented below.

S. Kaur, G. Kumbhar, and J. Sharma [17] presented Mixed Integer Non-Linear Programming (MINLP) method for finding the best location of multiple DG units in the distribution network to improve the stability of the system. The established MINLP shortens the difficulties by distributing the system into two models, namely Siting Planning Model (SPM) and Capacity Planning Model (CPM) that provide reduction in computational time and search space. In case of multiple DGs, optimal positions are same for MINLP techniques. However, this method gives more loss, which is slightly higher than the PSO algorithm.

D. B. Prakash, and C. Lakshminarayana [18] proposed multiple DG employments in the distribution network for decreasing the power loss and enhancing the voltage stability using Particle Swarm Optimization (PSO) Algorithm. In this concept, PSO was used to find out the optimal location and sizing of DG. However, this method only focuses on power loss issues, does not consider load restoration and cost-related problems. Additionally, this method easily falls into local optima in high dimensional space and it has a very low convergence rate.

P. Chiradeja, S. Yoomak, and A. Ngaopitakkul [19] presented an optimal placement of multiple DGs on distribution network to verify its reliability using Differential Evolution (DE) algorithm. In this, both DG size and its placement were connected nearby to the maximum load, so it minimized the active and reactive power losses. In the DE algorithm, modification of parameter is indispensable, so identical parameters may not assure the global optimal resolution.

Das, V. Mukherjee, and D. Das [20] developed symbiotic organism search algorithm for the best placement of DG in RDN. Power loss minimization can be attained with the help of this proposed algorithm. In this work, location of DG was depended upon generation and deterministic load demand. The outcome also showed better convergence characteristics and better computational efficiency of the proposed method. However, the voltage profile of the system is not considered while optimizing the DG location and size.

P. V. Babu, and S. P. Singh [21] presented NLP \& PLS approaches for the optimal allocation of DG in distribution system. By integrating General Algebraic Modelling System (GAMS), optimal sizing and allocation of DG in RDN were efficiently 
done. For that reason, power loss in the system was slightly decreased. However, Percentage loss reduction is same and optimum power factor is not attained in this method.

To overcome the above mentioned problems in the previous works, an effective optimization algorithm is proposed, named as Binary Particle Swarm Optimization (BPSO) which is described briefly in the below section.

\section{BPSO algorithm}

Particle Swarm Optimization (PSO) is presented as one of the most computation-efficient experimental method. Compared to Genetic Algorithm (GA) and other traditional methods, PSO delivers improved performance in DG placement complications. A new PSO method is suggested for selecting the variables from a selective space. This process becomes convenient when available DGs have their regular sizes in which the optimizer should choose the ideal ones. A typical IEEE 69-bus RDN is employed to point out the practicality of the proposed method. However, there are various optimization issues, which are discrete in nature and categorized as Combinatorial Optimization Difficulties. A "Continuous PSO" method would not suit here, so a "Binary PSO" algorithm is developed. Binary versions of the PSO has also been established that have higher benefits for resolving optimization issues. Therefore, the alterations make the PSO algorithm to work for these different types of problems. This solution creates the particle's bit string and constrain the value of velocity in the interval of $\left[\begin{array}{ll}0 & 1\end{array}\right]$. The velocity is stated as the possibility of a bit to achieve a value of 1 . BPSO appears like to be more appropriate to improve the efficiency of the distribution system. So, in this study, a novel BPSO algorithm is established for enlightening the steadiness of the system by reducing the power losses.

In PSO, the position and the velocity of every particle at the iteration $k$ in the search space are described by $X^{i}{ }_{k}$ and $V^{i}{ }_{k}$. The velocity of the particle $I$ in the iteration $k+1 P^{i}$ lbest is obtained from the following Eq. (1).

$$
\begin{aligned}
& V_{k+1}^{i}=\omega . V_{k}^{i}+C 1 \cdot R 1\left(P_{\text {lbest }}^{i}-X_{k}^{i}\right) \\
+C 2 . R 2\left(P_{\text {global }}^{i}-X_{k}^{i}\right) & \text { (1) }
\end{aligned}
$$

Where $R 1$ and $R 2$ are the random functions and $C 1, C 2$ are the training coefficients. $\omega$ is the inertia weight factor. $\omega$ can be obtained from the following Eq. (2).

$$
\left.\omega=\omega_{\max }-\left\{\left(\omega_{\max }-\omega_{\min }\right)-\mathrm{k}_{\max }\right)\right\} \times k
$$

Where $\mathrm{k}_{\max }$ is the number of the maximum iteration. At the end of each iteration, a new position for each particle is obtained by summing of old position and new velocity.

$$
X_{k+1}^{i}=X_{k}^{i}+V_{k+1}^{i}
$$

The particle swarm formula remained unchanged. A logistic transformation $S\left(V^{i}{ }_{k}\right)$ is used to accomplish this modification that is written in Eq. (4) and (5).

$$
S\left(V_{k+1}^{i}\right)=\operatorname{sig} \bmod e\left(V_{k+1}^{i}\right)=\frac{1}{1+\exp \left(V_{k+1}^{i}\right)}
$$

If rand $\propto S\left(V^{i}{ }_{k+1}\right)$ then: $X^{i}{ }_{k+1}=1$;

Else: $X_{k+1}^{i}=0$;

The function $S\left(V_{k}^{i}\right)$ is a sigmoid limiting transformation and rand is a quasi-random number selected from a uniform distribution in $[0,1]$. Eq. (6), (7) and (8) describe the limits of the particle's dimension.

$$
\begin{aligned}
& 1 \propto B_{i} \propto B_{\text {max }} \\
& 0 \propto P_{i} \propto P_{\text {max }} \\
& T_{i}=\left\{1,2, \ldots ., T_{f}\right\}
\end{aligned}
$$

\subsection{Optimal DG allocation}

The incorporation of DG into the distributed system may have an effect on the frequency, protection discrimination, voltage regulation and stability of the system. Improper choice of size and location of DG may produce more system losses. By optimal placement of DGs, distributed system take benefits of improving the reliability of supply. DG could be deliberated as one of the sustainable choices to alleviate some of the issues such as, low reliability, high power loss and poor power quality which helps in meets the energy requirement of ever-increasing loads. For a specific bus, the high value of DG produces less power loss and if the size of DG is greater than before, the losses will gradually increase. The output of active and reactive power of each DG unit must be selected in-between its minimum and maximum values which are expressed in Eq. (9) and (10). 


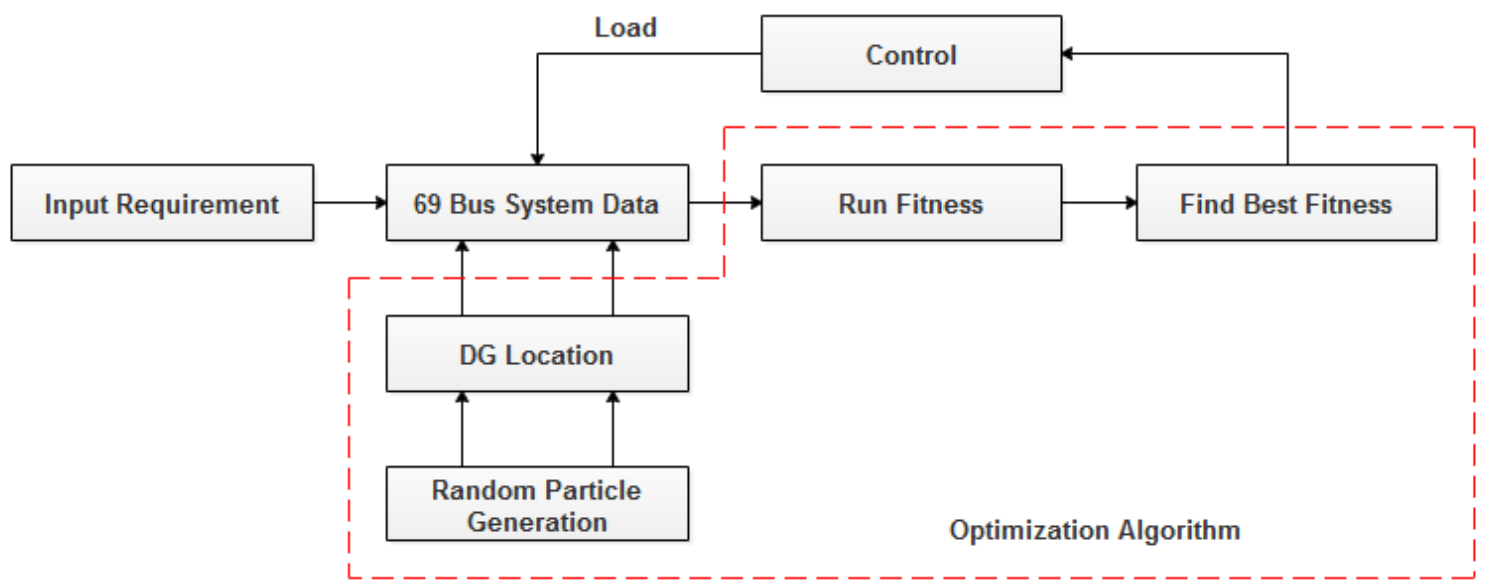

Figure. 1 Block diagram for allocation of DG

$$
\begin{aligned}
& P_{D G, i}^{\min } \leq P_{D g, i} \leq P_{D G, i}^{\max } \\
& Q_{G, \min } \leq Q_{G} \leq Q_{G, \max }
\end{aligned}
$$

Where $P_{D g, i}$ and $Q_{G}$ is nominal active and reactive power of $\mathrm{DG}, P^{\min }{ }_{D G, i}$ and $P^{\max }{ }_{D G, i}$ are minimum and maximum range of $D G$ 's active power, while $Q_{G, \min }$ and $Q_{G, \max }$ are minimum and maximum range of $\mathrm{DG}$ 's reactive power. So, the size of distribution network in terms of the load will plays an essential part in choosing the size of DG. Likewise, the position of DG also plays a key role in reducing the losses. The block diagram for the optimal placement in IEEE 69-bus system is shown in below Fig. 1 .

Step 1: Initialize the process with common control parameters that present inside the algorithm.

Step 2: Read the line data and bus data for IEEE 69 bus radial distribution system.

Step 3: Initially, the random particle generation will occur in that data. For that, load flow analysis is checked.

Step 4: Then, run the fitness function (Power loss, Voltage profile and Cost) of this particular data.

Step 5: From the data, find the best fitness values that are given to system data, which will be processed again for the next iteration.

Step 6: While considering the algorithm (with reconfiguration only), same load flow analysis is checked with a proposed methodology to find the best fitness values.

Step 7: The fitness values are to be calculated for random location for placing $\mathrm{DG}$, and it controls the real power and reactive power values.

Step 8: From the best values, $D G$ will be optimally located with the help of the proposed methodology, and multi-objectives are evaluated with proper placement of DG.

\subsection{BPSO reconfiguration}

The initial progress is completely based on continuous valued search spaces. BPSO is used for real value optimization issues once the real-binary transformation process is completed. While, in the Binary version of PSO, the following state of every particle is decided to conferring the agent's affinity to be zero or one. The location of particles changed by selecting the appropriate mutation bits. Then the particle may perceive to transfer near and far corners of the hypercube by flipping bits. One of the main issues to be addressed in the establishment of BPSO is how to interpret the velocity of a binary vector. BPSO methodology is used for solving the DG allocation problem. In this context, the procedure stated above is not used because of the level of randomness. Due to this randomness level, the constraint equation becomes very problematic, while running the program. To deal with the difficulty, BPSO selects the binary values 0 and 1 as a range of particles. Then the velocity is considered in the normal process; BPSO is a velocity limited process and it makes sure the resolutions which do not fall into the local optima. BPSO is used to replicate the mapping from particle velocity, probability should be selected, and it should confirm the outcome to be global optimal one.

\subsection{Flowchart for reconfiguration with BPSO}

BPSO used in the reconfiguration of the distribution system and it decides the operation of the switches. The main problems of this system is to select the sectionalizing switches. Moreover, this problem lies in two states, either open or close the sectionalizing switches. The binary values of 0 and 1 signifies the opening and closing of switches 


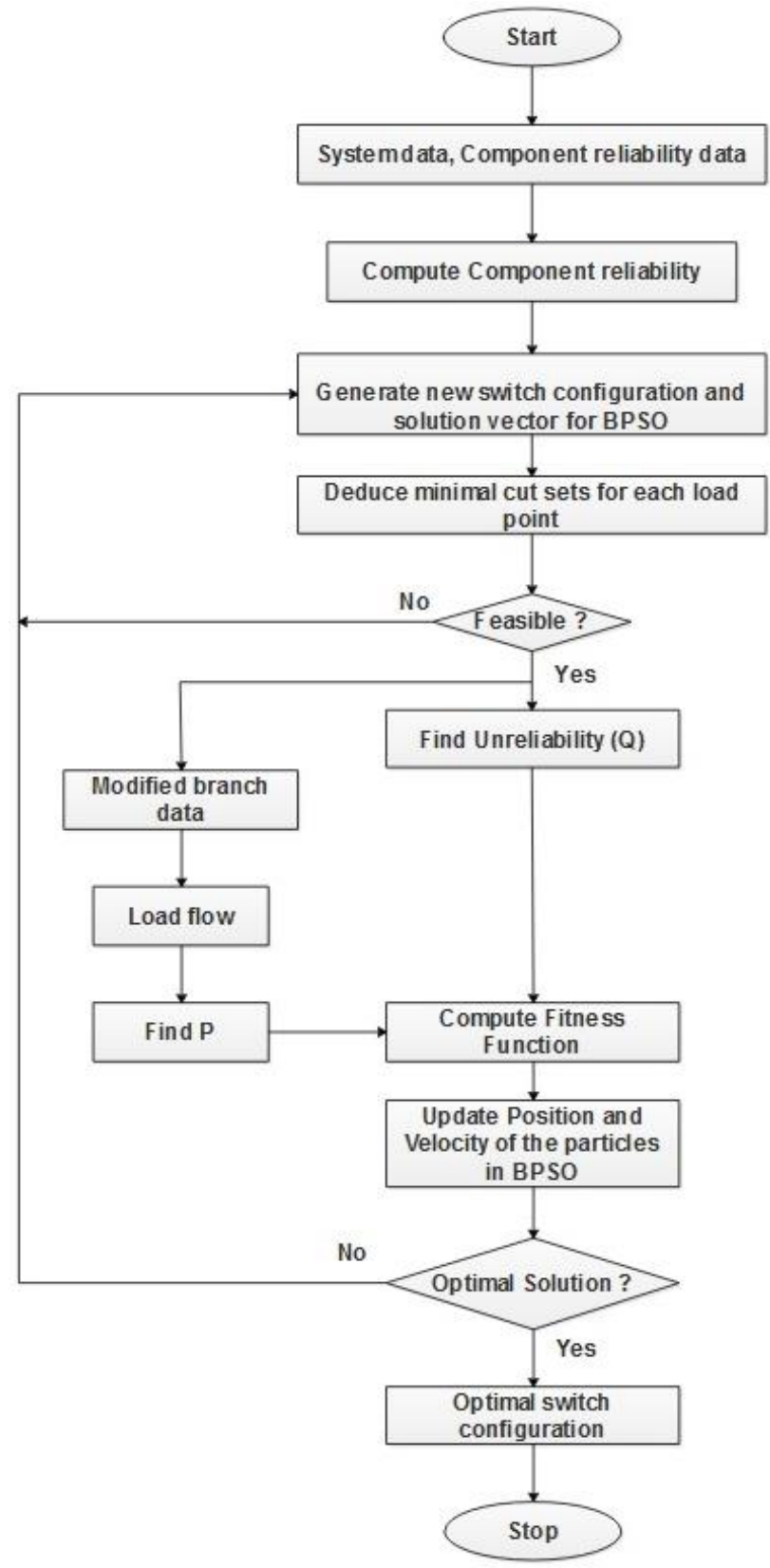

Figure. 2 Flowchart for the reconfiguration of power distribution system

respectively. The states of switch designated by binary vector. BPSO explored the binary vector that gives a solution for solving the reconfiguration issues when compared to other process. The flowchart for reconfiguration of power distribution system is given in Fig. 2.

Several swarm particles are exploited to get the resolution of the given issue. In the proposed method, BPSO procedure primarily creates the randomized velocity by loading the swarm values that have the dimensional matrix and it's treated as swarms. In the next, zero padding for the variable sig with the number of particles and dimensions, which created the randomized matrix called $r_{1}$ and $r_{2}$ Set the maximum iteration to check each node in the network for establishing the incidence matrix. Fitness function calculated with the help of velocity updation in randomized value updates particle swarm coordinates. Like this, the BPSO method is developed to simulate the IEEE 69 Bus distribution network.

\section{Result and discussion}

The optimization techniques implemented in this study have been analysed on standard radial networks consist of IEEE 69 bus systems. Ever since DGs are normally installed at only few number of locations, the set of exploratory solutions are obtained from each candidate solution which is not very large. However, some of the exploratory solutions may violate problem constraints and thus become infeasible. These issues are corrected by using BPSO algorithm. BPSO search algorithm used in searching within the group to improve search efficiency and avoid early maturing. In the proposed method, two major parameters of each DG determined using BPSO method. These major parameters are: size and location of each DG. BPSO identifies the test system through load flow, optimal DG placement and DG rating. The simulation results show that BPSO for the distribution network with DG, which can not only reduce the network loss and support system voltage but also improve the stability of the system. BPSO is suitable to search for the best switch combination of distribution network with DG. The simultaneous optimal placement of DG and optimal DG rating improve the power quality in terms of loss reduction and enhanced voltage profile have been compared and discussed. The effectiveness of the proposed BPSO method is investigated on 69-bus test distribution system. This system has 68 sectionalizing lines, 5 tie-lines and 8 feeders. The normally open switches are 69-73. The proposed method is programmed in MATLAB software. In the simulation of network, four scenarios are considered to analyse the superiority of the proposed technique. The simulated results are compared with the results of other techniques to assess the performance and effectiveness of the proposed technique.

Scenario I: The system with reconfiguration only;

Scenario II: The system with DG units only;

Scenario III: The system with reconfiguration and installation of single DG unit;

Scenario IV: The system with reconfiguration and installation of multi DG units; 


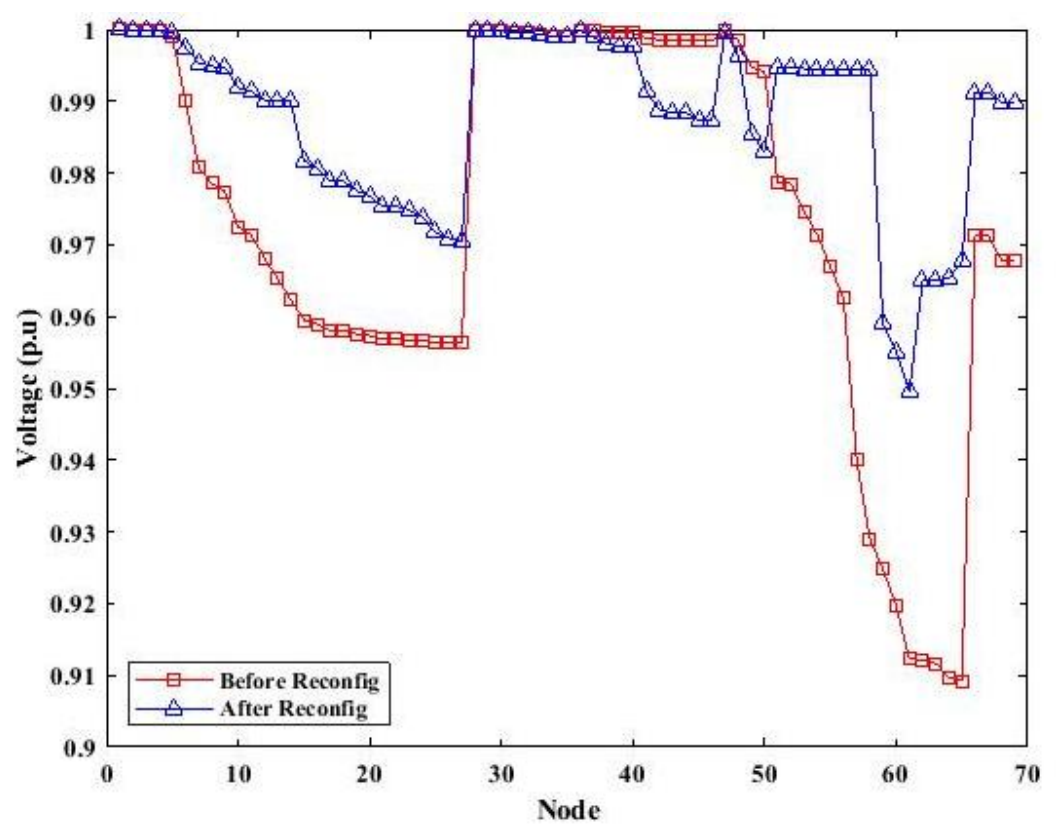

Figure. 3 Reconfiguration of power distribution system for first scenario

For considering scenario 1, the test bus system is carried out with only reconfiguration without the inclusion of DG units. The results for first scenario is shown in Fig. 3 and the values are tabulated in Table 1.

For considering scenario 2, the test bus system is carried out with only the inclusion of DG unit. The results for second scenario is shown in Table 2.

The results of second scenario are shown in Fig. 4 and Table 2 represents the optimal DG size without the reconfiguration for 69-bus distribution system. It can be concluded that optimal DG allocation with a size of $0.4 \mathrm{MW}$ harnessing a reduction in the total real power loss from 224.6 to $82.1119 \mathrm{~kW}$ that shows the $63.4886 \%$ of overall reduction. The percentage improvements in power losses from the base case show better results.

For considering scenario 3, the test bus system is carried out with reconfiguration and the inclusion of DG unit. The results for third scenario is shown in Table 3.

Table 3 represents the optimal DG size with reconfiguration for the IEEE 69-bus distribution system. It can be concluded that bus 39 is the best bus for optimal DG allocation with a size of 0.4 MW that produces reduction in the total real power loss from 224.6 to $46.9193 \mathrm{~kW}$ that shows the $79.1372 \%$ of overall reduction. The percentage improvements in power losses from the base case show better results. However, the total real power loss is reduced more due to the availability of reactive power generation source at load locations.
Table 1. Results for first scenario

\begin{tabular}{|c|c|c|}
\hline \multicolumn{2}{|c|}{ Simulation Results of 69 Bus Distribution Network } \\
\hline $\begin{array}{c}\text { Items (scenario } \\
\text { 1) }\end{array}$ & $\begin{array}{c}\text { BEFORE } \\
\text { Reconfiguration }\end{array}$ & $\begin{array}{c}\text { AFTER } \\
\text { Reconfiguration }\end{array}$ \\
\hline Tie switches & 6970717273 & 1456616970 \\
\hline Power loss & $224.9804 \mathrm{~kW}$ & $98.5952 \mathrm{~kW}$ \\
\hline $\begin{array}{c}\text { Power loss } \\
\text { reduction }\end{array}$ & ------------ & $56.1761 \%$ \\
\hline $\begin{array}{c}\text { Minimum } \\
\text { voltage: }\end{array}$ & $0.90919 \mathrm{pu}$ & $0.94947 \mathrm{pu}$ \\
\hline
\end{tabular}

Table 2. Results for second scenario

\begin{tabular}{|c|c|c|}
\hline \multicolumn{3}{|c|}{ Simulation Results of 69 Bus Distribution Network } \\
\hline $\begin{array}{c}\text { Items (scenario } \\
\text { 2) }\end{array}$ & BEFORE DG & AFTER DG \\
\hline Tie switches & 6970717272 & 6970717273 \\
\hline Power loss & $224.9804 \mathrm{~kW}$ & $82.1119 \mathrm{~kW}$ \\
\hline $\begin{array}{c}\text { Power loss } \\
\text { reduction }\end{array}$ & ---------- & $63.4886 \%$ \\
\hline Size of DG & $0.1018 \mathrm{MW}$ & $4 \mathrm{KW}$ \\
\hline $\begin{array}{c}\text { Minimum } \\
\text { voltage: }\end{array}$ & 0.9677 & 0.94693 \\
\hline
\end{tabular}

Table 3. Results for third scenario

\begin{tabular}{|c|c|c|}
\hline \multicolumn{2}{|c|}{ Simulation Results of 69 Bus Distribution Network } \\
\hline $\begin{array}{c}\text { Items (scenario } \\
\text { 3) }\end{array}$ & $\begin{array}{c}\text { BEFORE } \\
\text { Reconfiguration } \\
\text { with DG }\end{array}$ & $\begin{array}{c}\text { AFTER } \\
\text { Reconfiguration } \\
\text { with DG }\end{array}$ \\
\hline Tie switches & 6970717273 & 40605306 \\
\hline Power loss & $224.9804 \mathrm{~kW}$ & $46.9193 \mathrm{~kW}$ \\
\hline $\begin{array}{c}\text { Power loss } \\
\text { reduction }\end{array}$ & ----------- & $79.1372 \%$ \\
\hline $\begin{array}{c}\text { Minimum } \\
\text { voltage: }\end{array}$ & $0.90919 \mathrm{pu}$ & 0.94693 \\
\hline $\begin{array}{c}\text { Size (location of } \\
\text { DG) }\end{array}$ & $4 \mathrm{KW}$ & $4 \mathrm{KW} \mathrm{(39)}$ \\
\hline
\end{tabular}




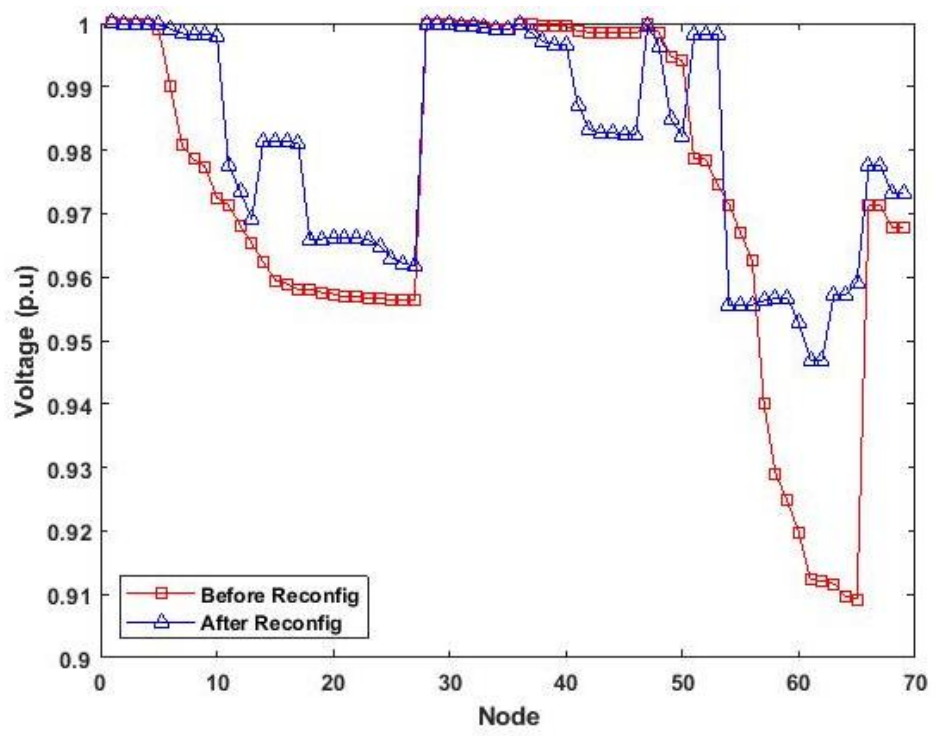

Figure. 4 Reconfiguration of power distribution system for second scenario

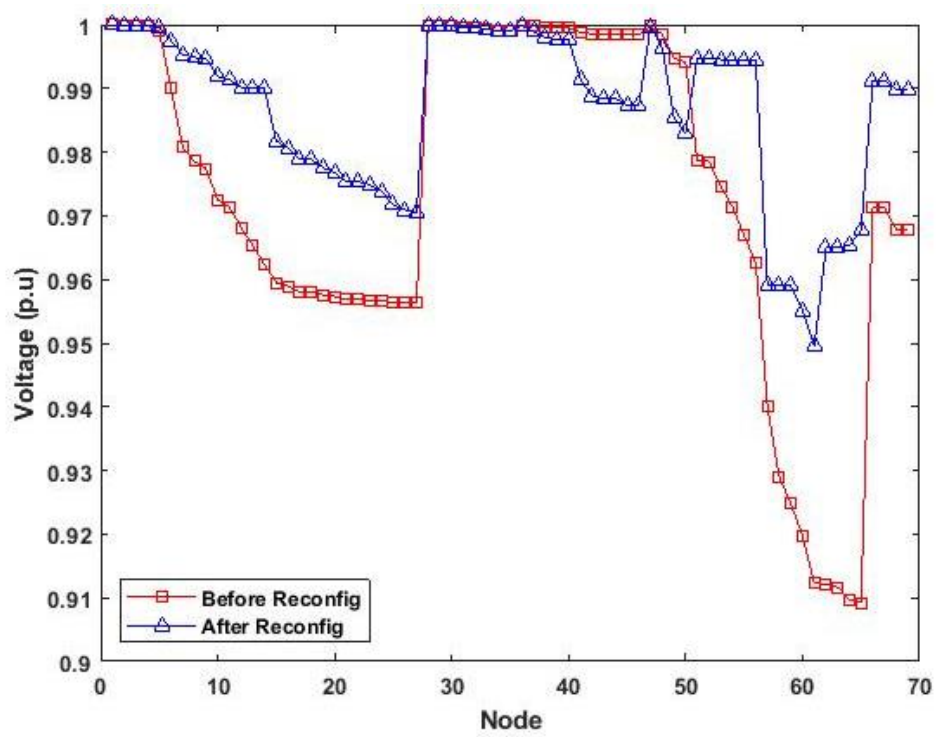

Figure. 5 Reconfiguration of power distribution system for fourth scenario

Table 4. Results for fourth scenario

\begin{tabular}{|c|c|c|}
\hline \multicolumn{2}{|c|}{ Simulation Results of 69 Bus Distribution Network } \\
\hline $\begin{array}{c}\text { Items (scenario } \\
\text { 4) }\end{array}$ & $\begin{array}{c}\text { BEFORE } \\
\text { Reconfiguration } \\
\text { with DGs }\end{array}$ & $\begin{array}{c}\text { AFTER } \\
\text { Reconfiguration } \\
\text { with DGs }\end{array}$ \\
\hline Tie switches & 6970717273 & 1714481336 \\
\hline Power loss & $224.9804 \mathrm{~kW}$ & $35.9239 \mathrm{~kW}$ \\
\hline $\begin{array}{c}\text { Power loss } \\
\text { reduction }\end{array}$ & ---------- & $84.0263 \%$ \\
\hline $\begin{array}{c}\text { Minimum } \\
\text { voltage: }\end{array}$ & $0.90919 \mathrm{pu}$ & $0.95907 \mathrm{pu}$ \\
\hline $\begin{array}{c}\text { Size (location of } \\
\text { DG) }\end{array}$ & $4 \mathrm{KW}$ & $4 \mathrm{KW} \mathrm{(21} \mathrm{32} \mathrm{63)}$ \\
\hline
\end{tabular}

For considering scenario 4, the test bus system is carried out with reconfiguration and the inclusion of multi DG units. The results for fourth scenario is shown in Table 4.

Table 4 represents the optimal DG size with reconfiguration for the IEEE 69-bus distribution system. Fig. 5 shows the voltage profile for the fourth scenario with reconfiguration technique. It can be concluded that bus 21,32, 63 is the best bus for optimal DG allocation with a size of $0.4 \mathrm{MW}$ which harnessing a reduction in the total real power loss from 224.6 to $35.9239 \mathrm{~kW}$ which shows $84.0263 \%$ of overall reduction. The percentage improvements in power losses from the base case show better results that are shown in comparison Table 5 and 6.

From the above results, better voltage regulation 
Table 5. Comparison table for all scenarios

\begin{tabular}{|c|c|c|}
\hline Base case & Existing Methods [22] & BPSO Algorithm \\
\hline Scenario 1 (Only & Tie switch $=6918135661$ & Tie switch $=1456616970$ \\
Reconfiguration) & Power loss $=99.35$ & Power loss $=98.5952$ \\
& Power loss reduction $=55.85 \%$ & Power loss reduction $=56.1761 \%$ \\
& Min voltage $=0.9428$ & Min voltage $=0.94947$ \\
\hline Scenario 2 (Only DG) & Tie switch $=6970717272$ & Tie switch $=6970717273$ \\
& Power loss $=86.77$ & Power loss $=82.1119$ \\
& Power loss reduction $=61.43 \%$ & Power loss reduction $=63.488 \%$ \\
& Min voltage $=0.9697$ & Min voltage $=0.9494$ \\
\hline Scenario 3 & Tie switch $=6918135661$ & Tie switch $=40605306$ \\
(Reconfiguration with & Power loss $=51.30$ & Power loss $=46.9193 \mathrm{~kW}$ \\
single DG) & Power loss reduction $=77.2 \%$ & Power loss reduction $=79.137 \%$ \\
& Min voltage $=0.9619$ & Min voltage $=0.94693$ \\
\hline Scenario 4 & Tie switch $=6917135861$ & Tie switch $=1714481336$ \\
Peconfiguration with multi & Power loss $=40.30$ & Power loss $=35.9239 \mathrm{~kW}$ \\
DGs) & Power loss reduction $=82.08 \%$ & Power loss reduction $=84.026 \%$ \\
& Min voltage $=0.9736$ & Min voltage $=0.95907$ \\
& DG size (location) $=1.0666(61), 0.3525$ & DG size (location) $=0.4(21), 0.4(32)$, \\
& $(60), 0.4527(62)$ & $0.4(63)$
\end{tabular}

Table 6. Comparison table for final scenario

\begin{tabular}{|c|c|c|c|}
\hline Base case & $\begin{array}{c}\text { Genetic Algorithm with } \\
\text { capacitor placement [23] }\end{array}$ & $\begin{array}{c}\text { Stud Krill Herd Algorithm } \\
\text { (SKHA) [24] }\end{array}$ & BPSO Algorithm \\
\hline Scenario 4 & Power loss $=99.742$ & Power loss $=99.742$ & Power loss $=35.9239 \mathrm{~kW}$ \\
(Reconfiguration & Min voltage $=0.95814$ & Power loss reduction $=$ & Power loss reduction $=84.026 \%$ \\
with multi DGs) & DG size (location) $=0.4(60)$, & $69.0967 \%$ & Min voltage $=0.95907$ \\
& $0.4(62), 0.4(64)$ & Min voltage $=0.95814$ & DG size $($ location) $=0.4(21)$, \\
& & DG size (location) $=$ & $0.4(32), 0.4(63)$ \\
& & $1719.0677[61], 370.8802$ & \\
& & {$[17] 527.1736[11]$} & \\
& & & \\
\end{tabular}

and much reduction in power losses can be obtained without encountering adverse problems in power system operation. In addition, BPSO is more fast and robust in solving radial distribution systems especially large ones. The advantage of this method over other methods is that the sub-problems can be solved using algorithms that can deal with a very large number of variables. Moreover, another benefit of this algorithm is that it updates the multipliers adaptively whose outcomes have fast solution and more precise. These advantages have been proven through application to a large test system with a large number of variables. The applied methodology in this research has attained much reduction in real power losses and better improvement in voltage profile. The Table 5 shows the comparison tables for all cases along with existing systems. Table 6 shows the comparison for final scenario. The performance and efficiency of distribution network reconfiguration are largely dependent on an efficient search algorithm. BPSO is a swarm intelligence optimization algorithm. The principle of BPSO is simple, robust and easy to achieve. The results showed that, in case of voltage problem, algorithm could improve voltage to a better limit, while keeping the losses reduced.

\section{Conclusion}

In this research work, BPSO algorithm is applied for resolving optimal distribution network reconfiguration and optimal DG employment with the objective of decreasing power loss and enhancing voltage profile. At first, the algorithm is exercised for resolving optimal DG placement that assesses optimal allocation for connecting DG and their significance for solving reconfiguration is a transient manner. The obtained outcomes clearly indicate that scenario IV (Multi DG installation with network reconfiguration) is found to be more effective in reducing the power loss from 224.9804 to $35.9239 \mathrm{KW}$ with the reduction of $84.026 \%$ compared to the other scenarios. Moreover, the voltage profile of the system improved from 0.95814 to 0.95907 while inserting multi DG units with $0.4 \mathrm{MW}$ size. To demonstrate the efficiency, 
BPSO algorithm is compared with genetic algorithm (GA) and harmony search algorithm (HAS). In view of the uncomplicatedness and rapid presentation of this BPSO algorithm, one can use it in the intelligent systems with a number of buses in real time applications. In addition, this algorithm is valuable for investigating remaining systems that support in the development of the upcoming system, which is specifically appropriate for a large-scale real-world system.

\section{References}

[1] I. B. Hamida, S. B. Salah, F. Msahli, and M. F. Mimouni, "Optimal network reconfiguration and renewable DG integration considering time sequence variation in load and DGs", Renewable Energy, Vol.121, pp.66-80, 2018.

[2] P. Mehta, P. Bhatt, and V. Pandya, "Optimal selection of distributed generating units and its placement for voltage stability enhancement and energy loss minimization", Ain Shams Engineering Journal, Vol.9, No.2, pp.187-201, 2015.

[3] O. A. Zongo and A. Oonsivilai, "Optimal placement of distributed generator for power loss minimization and voltage stability improvement", Energy Procedia, Vol.138, pp.134-139, 2017.

[4] U. Sultana, A. B. Khairuddin, M. M. Aman, A. S. Mokhtar, and N. Zareen, "A review of optimum DG placement based on minimization of power losses and voltage stability enhancement of distribution system", Renewable and Sustainable Energy Reviews, Vol. 63, pp. 363-378, 2016.

[5] H. Doagou-Mojarrad, G. B. Gharehpetian, H. Rastegar, and J. Olamaei, "Optimal placement and sizing of DG (distributed generation) units in distribution networks by novel hybrid evolutionary algorithm", Energy, Vol.54, pp. 129-138, 2013.

[6] A. K. Singh and S. K. Parida, "Novel sensitivity factors for DG placement based on loss reduction and voltage improvement", International Journal of Electrical Power \& Energy Systems, Vol.74 pp.453-456, 2016.

[7] R. Ishak, A. Mohamed, A. N. Abdalla, and M. Z. C. Wanik, "Optimal placement and sizing of distributed generators based on a novel MPSI index", International Journal of Electrical Power \& Energy Systems, Vol.60, pp.389-398, 2014.
[8] M. M. Aman, G. B. Jasmon, A. H. A. Bakar, and H. Mokhlis, "A new approach for optimum simultaneous multi-DG distributed generation Units placement and sizing based on maximization of system loadability using HPSO (hybrid particle swarm optimization) algorithm", Energy, Vol. 66, pp.202-215, 2014.

[9] B. Singh and B. J. Gyanish, "Impact assessment of DG in distribution systems from minimization of total real power loss viewpoint by using optimal power flow algorithms", Energy Reports, Vol. 4, pp.407417, 2018.

[10] C. Yammani, S. Maheswarapu, and S. Matam, "Multiobjective optimization for optimal placement and size of $\mathrm{dg}$ using shuffled frog leaping algorithm", Energy Procedia, Vol.14, pp.990-995, 2012.

[11] A. M. Abd-Rabou, A. M. Soliman, and A. S. Mokhtar, "Impact of DG different types on the grid performance", Journal of Electrical Systems and Information Technology, Vol.2, No.2, pp.149-160, 2015.

[12] D. Q. Hung, N. Mithulananthan, and Y. L. Kwang, "Optimal placement of dispatchable and nondispatchable renewable DG units in distribution networks for minimizing energy loss", International Journal of Electrical Power \& Energy Systems, Vol.55, pp.179-186, 2014.

[13] B. Mohanty and S. Tripathy, "A teaching learning based optimization technique for optimal location and size of DG in distribution network", Journal of Electrical Systems and Information Technology, Vol.3, No.1, pp.33-44, 2016.

[14] S. A. ChithraDevi, L. Lakshminarasimman, and R. Balamurugan, "Stud Krill herd Algorithm for multiple DG placement and sizing in a radial distribution system", Engineering Science and Technology, an International Journal, Vol.20, No.2, pp.748-759, 2017.

[15] M. M. Aman, G. B. Jasmon, H. Mokhlis, and A. H. A. Bakar, "Optimal placement and sizing of a DG based on a new power stability index and line losses", International Journal of Electrical Power \& Energy Systems, Vol.43, No.1, pp.1296-1304, 2012.

[16] S. Sahu, A. K. Barisal, and A. Kaudi, "Multiobjective optimal power flow with DG placement using TLBO and MIPSO: A comparative study", Energy Procedia, Vol.117, pp.236-243, 2017.

[17] S. Kaur, G. Kumbhar, and J. Sharma, "A MINLP technique for optimal placement of multiple DG units in distribution systems", 
International Journal of Electrical Power \& Energy Systems, Vol.63, pp.609-617, 2014.

[18] D. B. Prakash and C. Lakshminarayana, "Multiple DG placements in distribution system for power loss reduction using PSO Algorithm", Procedia Technology, Vol.25, pp.785-792, 2016.

[19] P. Chiradeja, S. Yoomak, and A. Ngaopitakkul, "Optimal Allocation of Multi-DG on Distribution System Reliability and Power Losses Using Differential Evolution Algorithm”, Energy Procedia, Vol.141, pp.512 $-516,2017$.

[20] B. Das, V. Mukherjee, and D. Das, "DG placement in radial distribution network by symbiotic organisms search algorithm for real power loss minimization", Applied Soft Computing, Vol.49, pp.920-936, 2016.

[21] P. V. Babu and S. P. Singh, "Optimal Placement of DG in Distribution network for Power loss minimization using NLP \& PLS Technique", Energy Procedia, Vol.90, pp.441454, 2016.

[22] R. S. Rao, K. Ravindra, K. Satish, and S. V. L. Narasimham, "Power loss minimization in distribution system using network reconfiguration in the presence of distributed generation", IEEE Transactions on Power Systems, Vol.28, No.1, pp.317-325, 2013.

[23] B. J. Rani and A. S. Reddy, "Optimal Distribution Planning with Finite Value Dg Placement: A GA Based Approach", International Journal of Applied Engineering Research, Vol.10, No.44, pp. 30932-30937, 2015.

[24] S.S. ChithraDevi, L. Lakshminarasimman, and R. Balamurugan, "Stud Krill herd Algorithm for multiple DG placement and sizing in a radial distribution system", Engineering Science and Technology, an International Journal, Vol.20, No.2, pp.748-759, 2017. 